\title{
Understanding and predicting ENSO
}

\author{
D. S. Battisti and E. S. Sarachik \\ Department of Atmospheric Sciences, University of Washington, Seattle
}

\section{Introduction}

Throughout the 1960's and 1970's, oceanographers referred to the large-scale warming of the equatorial eastern and central Pacific as El Niño. This anomalous warming was later shown to be associated with anomalies in the upper ocean thermal structure throughout the equatorial Pacific Ocean. At about the same time, scientists realized that the Southern Oscillation was intimately related to the large-scale changes in the tropical Pacific Ocean. In brief, the Southern Oscillation represents the variability in the Indo-Pacific Walker circulation in the tropics, and is manifest as a displacement of the convection over the maritime continent, and is associated with large-scale anomalies in the surface wind and sea level pressure throughout the tropical Pacific (and into the Indian Ocean) basin.

It became clear by the beginning of the 1980's that the El Niño and Southern Oscillation are intimately related, with the large-scale warming (El Niño) coordinated with a relaxation of the trade winds throughout Pacific Ocean and a displacement of the atmospheric convection into the central Pacific from the maritime continent. Scientists coined the acronym ENSO to uniquely describe this large-scale, interannual climate phenomenon. Throughout the 1980's, theoretical and modeling studies demonstrated that ENSO (hence, El Niño) is a phenomenon that is inherently due to the coupling between the atmosphere and ocean, and that the crucial interactions between these media are in the tropical Pacific. Important observational studies led to empirical evidence that linked the tropical ENSO events to seasonal climate anomalies over Australia, South America and into the tropical Indian ocean, and to anomalies in the midlatitude $\mathrm{N}$. Hemisphere climate, especially over the N. Pacific Ocean and over central and North America during winter. Rasmusson and Wallace [1983] provide a succinct presentation of the salient features of the tropical ENSO phenomenon, with a more recent and comprehensive overview of the tropical and global characteristics of the ENSO phenomenon available in the volume edited by Glanz et al. [1991]. Finally, a report on El Niño and climate that is appropriate for the general public is found in Wallace [1994].

The last four years have coincided with the second half of TOGA (Tropical Ocean/Global Atmosphere),

Copyright 1995 by the American Geophysical Union. an international program devoted to understanding and predicting the interannual variability characteristic of ENSO. Progress in the second half of TOGA has been impressive and has gone a long way towards fulfilling the original goals of the program.

This paper will review the progress made in understanding ENSO during the last four years, in particular in the observing systems set up to see the evolving warm and cold phases in the tropical Pacific and in the modeling and theoretical advances devised to explain them. The paper will also briefly review the new field of ENSO prediction, in particular the progress of combining coupled atmosphere-ocean models with the real-time data provided by the TOGA Observing System. One of the truly exciting advances is the application of these forecasts for social and economic utility: some examples of current applications will be indicated.

\section{Observing ENSO}

In 1982, when the need for focussed ENSO studies was just being discussed, the strongest warm phase of ENSO of this century was developing in the Pacific Ocean without the scientific community being in the least aware of it. The destructive impacts of the huge 1982/3 warm event in the Pacific were felt as far away as coastal North America and resulted in disaster declarations by the Governors of California, Oregon, and Washington. It was subsequently realized that a fundamental requirement for all future ENSO studies was a capability to observe the surface and near surface of the tropical Pacific in real time. The last four years have seen that capability reach fruition.

The oceanic component of the TOGA Observing System consists of expendable bathythermograph (XBT) observations from Voluntary Observing Ships (VOS), a sea-level network, a drifter array which measures sea surface temperature (SST) and position, and the TOGA Tropical Atmosphere/Ocean (TAO) Array [Hayes et al., 1991], all telemetering in real time to the Global Telecommunication System, from which the data is available for research and prediction purposes (see $\mathrm{Na}$ tional Research Council [1994] for a complete discussion).

As a result of the TOGA Observing System, we can now observe the state of the upper tropical Pacific Ocean in real time; we are developing accurate climatologies of upper ocean thermal structure, surface winds, and upper ocean currents; we have developed assimilation techniques so that fields of data for the entire tropical Pacific are continuously available [Leetmaa 
and $\mathrm{Ji}, 1989]$; we are gradually coming to understand the nature of the annual, interannual, and longer term variability of the Pacific; and we use the surface data routinely for operational weather forecasting and the surface and subsurface data for experimental short term (i.e., seasons to a year) climate forecasting. Monthly summaries of the observations are available in the Climate Diagnostics Bulletin where instructions for access to the data over Internet (via ftp) are also given.

While the TOGA Observing System is itself an extraordinary achievement, the intimate interplay between observations and predictions that has developed during TOGA makes the study of ENSO variability and predictability particularly exciting and fruitful.

\section{Advances in the Theory and Modeling of ENSO}

The recent advances in the theory of the variability in the tropics due to the coupling between the atmosphere and ocean falls into four categories: the physics of ENSO (including attempts to verify some existing hypotheses), the irregularity of ENSO events, the theory of ENSO prediction, and the potential for interactions between the annual cycle and the ENSO variability.

\subsection{The Physics of ENSO}

The majority of the theoretical activities on the low frequency variability in the tropical Pacific are focussed on understanding the conditions that support various coupled atmosphere/ocean modes. The two modes that represent the extrema of the continuum of unstable coupled atmosphere/ocean modes are, in simplest form, the slow westward propagating advective "Rossby" mode described first by Gill [1985] and more completely by Hirst [1986], and an eastward propagating destabilized Kelvin-like mode [Philander et al., 1984; Yamagata, 1985]. Hirst [1988] showed that in a homogeneous (large) bounded basin, these two modes will propagate and continuously regenerate at interannual timescales.

These extrema in the modes of atmosphere/ocean instability are unattractive candidates for explaining nature's ENSOs for three reasons. First, in the Pacific Ocean there is a fundamental east-west asymmetry in the basic state (e.g., a colder eastern basin). Second, the observed SST anomalies do not seem to propagate systematically. Finally, from observations, the timescales associated with the local air-sea interaction are comparable to the dynamical adjustment time of the tropical ocean. For the destabilized coupled Rossby mode to exist the anomalies in upwelling must be a small term in the heat budget of the ocean mixed layer. However, the existing buoy data and the analysis of hindcast simulations of the ocean response during ENSO using ocean general circulation models indicate that throughout the eastern and central equatorial basin, subsurface temperature anomalies and upwelling anomalies are an important process in changing SST. For the destabilized eastward propagating Kelvin mode to be favored, hor- izontal SST advection must be unimportant and the adjustment (or mechanical damping) timescales of the ocean must be long compared with the timescales associated with local SST changes, neither of which is true for the Pacific Ocean. Clearly, the pure destabilized propagating modes noted above are not relevant to nature.

When the entire observational record is considered, the robust tropical features of the observed ENSO are as follows: (1) quasi-stationary SST anomalies in the eastern and central Pacific; (2) at event onset, a relaxation of the trade winds associated with positive SST anomalies; (3) there is a deepening in the east and a shoaling in the west of the thermocline along the equator; (4) prior to the peak of the ENSO event, the anomalously deep thermocline in the eastern/central Pacific begins to return to climatological values. In addition, there is usually an increase in the trades in the far western $\mathrm{Pa}$ cific one or two seasons prior to the onset of the ENSO event. $^{1}$

Presently, the theory for ESNO events that best fits with the robust observations (1-4) noted above is the delayed-oscillator theory of ENSO, put forward by Suarez and Schopf [1988] and Battisti and Hirst [1989]. The delayed oscillator mechanism for ENSO incorporates the important observational constraint that the timescale of the basin adjustment is comparable to the timescale associated with the local air-sea interactions. In addition, the delayed oscillator mechanism postulates that the dynamical adjustments in the eastern half of the ocean basin affect the SST (and consequently the atmospheric circulation) vis a vis changing the temperature of the water that is subsequently entrained into the surface mixed layer. Both the Suarez and Schopf [1988] and the Battisti and Hirst [1989] delayed oscillator models were formulated by assuming that the coupled atmosphere/ocean mode was stationary and trapped to the eastern basin. ${ }^{2}$ It is important to note that if nature's ENSO events are captured by the delayed oscillator mechanism, the latter theory also provides a theoretical basis for the role of the ocean memory in ENSO and, thus, the expectation that the state of the tropical Pacific climate system (i.e., ENSO) should be predictable for lead times of (at least) one year.

In a series of papers, Jin and Neelin [1993a,b] and Neelin and Jin [1993] explored the atmosphere/ocean instabilities that developed in a hierarchy of coupled models, including an ocean general circulation model (GCM) coupled to a statistical atmosphere model, and a simplified equatorial strip atmosphere/ocean model in

\footnotetext{
${ }^{1}$ In this discussion, the "peak" of ENSO is defined as the time that the large-scale SST anomalies reach a maximum, and "onset" is loosely defined as the time immediately prior to there being measurable large-scale positive SST anomalies.

${ }^{2}$ Suarez and Schopf postulated the ocean dynamical adjustment time is large compared with the timescale associated with the air-sea interactions and, thus, an inherently nonlinear coupled system.
} 
which only the important ocean thermodynamics that are identified from the Zebiak and Cane [1987] coupled model are retained. In these studies, they explore the continuum of coupled atmosphere/ocean modes that exist in the parameter space mapped out by varying the coupling strength, the ratio of the ocean dynamical adjustment time to the timescale associated with the SST changes, and the relevant strength of the upwelling vs. horizontal advection terms in the ocean thermodynamic equation. By varying the parameters to more realistic values, introducing increasingly complete ocean (SST) thermodynamics, and tracking the eigenmodes, Jin and Neelin demonstrated how the extreme (idealized) eigenmodes that arise from the homogeneous basic state problem (see, e.g., Hirst, [1988]) give way to an increasing realistic stationary dominant eigenmode, the delayed oscillator. It is clear from these papers, and the summary review by Neelin et al. [1994], that unless some important physics is being neglected (e.g., cloud feedbacks) the delayed-oscillator mode is rather robust and is likely to be the dominant unstable atmosphere/ocean mode in nature.

The delayed oscillator theory for ENSO is remarkably consistent with the ENSO events that occur in the Hamburg coupled atmosphere/ocean general circulation model [Latif et al., 1993], and it is qualitatively consistent with the results from the Geophysical Dynamics Laboratory (GFDL) coupled high resolution model discussed by Philander et al. [1992]. The ENSO events from the aforementioned models also share many similarities with the observed canonical [Rasmusson and Carpenter, 1982] ENSO event. However, the interannual variability in a third coupled atmosphere/ocean GCM, reported by Nagai et al. [1992], is rather weak compared to that observed and fits the delayed oscillator model of ENSO only during the evolution and decay of the ENSO event: the Rossby debris from the cold events does not always kick off the next warm event (see also section 3.4). Finally, Lau et al. [1992] reported on the tropical interannual variability from a coupled atmosphere/ocean GCM in which the Kelvin waves are significantly distorted by the combination of numerics with a coarse ( $4^{\circ}$ latitude) resolution [see $\mathrm{Ng}$ and $\mathrm{Hsieh}$, 1994]. Moreover, the latitudinal extent of the upwelling is known to be fundamental to the nature of the interannual variability from theoretical constraints [Wakata and Sarachik, 1992]. In the low-resolution model reported on by Lau et al., the upwelling is necessarily diffuse. As a result and consistent with all the results above, the interannual variability in the low-resolution model is well described by a slowly (westward) propagating destabilized Rossby mode.

To what extent is the delayed oscillator theory for ENSO supported by the observations? Kessler [1990] has examined the observed wind stress data, the sea surface temperature anomalies, and the variability in the upper ocean thermal structure from the VOS XBT data. He concluded that the variability in the thermocline was consistent with that expected from the delayed oscillator theory. (Wakata and Sarachik [1991] reached the same conclusion by examining the response of a shallow water model to the observed (Florida State University) wind stress anomalies.)

While the aforementioned robust observations of the development and termination of an ENSO event are consistent with delayed oscillator theory, there are clearly inconsistencies between the robust observations during event onset. Specifically, the strengthening of the trades that usually precedes the event is not a feature of the delayed oscillator theory or of the intermediate atmosphere/ocean models from which the theory is derived. Li and Clarke [1994] (hereafter LC) used equatorial wave theory and tide gauge data to construct a record of the "observed" western Pacific Kelvin amplitude. They correlated the reconstructed Kelvin signal with an index of the large scale zonal wind anomaly and argued the structure of the lag-correlation curve was inconsistent with the delayed oscillator theory of ENSO. The physics associated with the correlation structure reported in LC was examined in a complimentary analysis by Mantua and Battisti [1994a], whereby an ocean model was forced with the observed windstress anomalies to obtain the western Pacific Kelvin signal (which was highly correlated with that derived by LC using independent data and methods). They demonstrated that "delayed oscillator theory" did account for the termination of warm (ENSO) events but the cold events are not usually terminated by the (delayed oscillator) ocean adjustment process. Thus, the overall correlations between the "observed" Kelvin amplitude and the wind stress are degraded significantly from pure delayed oscillator theory: in nature, the ENSO events are not nearly periodic. Similar conclusions are reached by $\mathrm{Na}$ gai et al. [1992] in their diagnosis of the tropical Pacific variability in a coupled atmosphere/ocean general circulation model.

Finally, Penland and Magorian [1993] and Penland and Sardeshmukh [1995] have hypothesized that the tropical Pacific atmosphere/ocean system is stable in a global sense, and that the ENSO variability is best thought of as a response of the tropical Pacific system to stochastic forcing. Thus, without an external noise forcing the system there would be no ENSO events. This hypothesis for ENSO is, apparently, at odds with the all the aforementioned studies on unstable modes of variability. If the hypothesis is correct, the the intermediate level atmosphere/ocean coupled models and the hybrid numerical ocean/statistical atmosphere coupled models should demonstrate stable, not oscillatory, behavior.

\subsection{Irregularity of ENSO}

Investigators have hypothesized many reasons for irregularity in the ENSO cycle. These are loosely grouped into four categories: (1) noise internal to either the atmosphere or ocean and independent of the coupling between that media; (2) inherent nonlinearity of the coupled atmosphere/ocean system (or in the coupling itself); (3) changes in the external forcing; (4) interactions between ENSO and the seasonal cycle (discussed in section 3.3). 
3.2.1. Internal noise. The cause for irregularity of ENSO has been attributed to noise internal to the atmosphere or ocean. Specifically, investigators have discussed the impact of the atmospheric weather, ranging in timescales from synoptic to interannual. Explicitly or implicitly, weather is invoked in the studies of Suarez and Schopf [1988], Zebiak [1989], Goswami and Shukla [1991], and Penland and Margorian [1993].

3.2.2. Nonlinearity. Munnich et al. [1991] have examined a streamlined, nonlinear atmosphere/ocean model and found that irregular interannual variability can result from the coupling of the atmosphere and ocean. Recently, Mantua [1994] and Mantua and Battisti [1994a] analyzed the Zebiak/Cane numerical model and demonstrated the irregularity in the model ENSO cycle was due to the interaction between two coupled unstable atmosphere/ocean modes. They concluded that, though an individual model ENSO cycle was well described by the delayed oscillator theory, the irregularity in the model ENSO events is due to deterministic, nonlinear processes in the model (cf., section 3.2.1) associated with the interactions between the unstable modes.

3.2.3. External forcing and decadal-to-century variability of ENSO. Various investigators have proposed that disturbances propagating into the tropical Pacific from the extratropics or the Indian Ocean can trigger or modify the ENSO cycle (see, e.g., Barnett et al. [1989] and section 3.2.1). More recently, preliminary investigations of the effect of changing atmospheric $\mathrm{CO}_{2}$ concentration on the tropical Pacific coupled interannual variability have been reported by Meehl et al. [1993], Graham et al. [1995], and Knutson and Manabe [1995]. However, in these studies of ENSO in an increased $\mathrm{CO}_{2}$ environment, there are serious numerical and methodological issues that arise, and the relevance of the results from these studies to Nature is not certain. Finally, the definitive study of Mass and Portman [1989] eliminates volcanic eruptions as a forcing of ENSO.

It is not clear, however, to what extent the spectrum of interannual variability in the tropical Pacific is stationary: the direct observational data does not exist to adequately define even the multidecadal variability in the tropical Pacific. The low frequency modulation of ENSO could come about from nonlinearity in the coupled atmosphere/ocean/land system, involving either the upper ocean, or changes in the (shallow) thermohaline circulation in the subtropics. Unfortunately, the present intermediate models of the coupled atmosphere/ocean system are inappropriate for such studies, and it is not yet possible to investigate the coupled GCMs for the thousands of model years that are required to examine these issues.

It may be possible to address these issues, however, from the increasing variety and geographical extent of the proxy data from paleoclimate studies. For example, proxy data exists for equatorial upwelling [Lea et al., 1989] and extrema in wind stress anomalies [Shen et al., 1992a,b; Cole et al., 1993] from tropical corals. Proxy indicators have been derived for the Southern Oscillation Index from coral [Cole and Fairbanks, 1990] and tree ring data [Stahle and Cleaveland, 1993]. Finally, there is a connection between ENSO and high dimethylsulfide (DMS) marine emissions at high southern latitudes [Legrand and Feniet-Saigne, 1991].

\subsection{Seasonal Cycle and ENSO}

Is the seasonal cycle necessary for ENSO to be realized? Not likely: Many models without an annually varying sun have proven successful at simulating interannual variability that is ENSO-like. These models include the intermediate coupled numerical atmosphere/ocean models (see, e.g., Suarez and Schopf [1988]; Mantua [1994]) and coupled atmosphere/ocean GCMs [Latif et al., 1993; Philander et al., 1992]. Is the seasonal cycle fundamental to the irregularity in the ENSO events? All of the aforementioned models are run without an annually varying sun and the ENSO events that they produce occur irregularly. However, ENSO is sufficiently tied to the annual cycle that it is useful to think of a canonical ENSO event, formed by compositing observations fixed to the calendar year [Rasmusson and Carpenter, 1982].

3.3.1. The general circulation models. Recently, simulations using coupled atmosphere/ocean general circulation models that include an annually varying solar forcing have been reported by Nagai et al. [1992] and Robertson et al. [1995]. In both of these studies, the annual cycle in the tropical Pacific SST, surface fluxes, and wind are qualitatively consistent with that observed. ${ }^{3}$ And both models also contain coordinated atmosphere and surface ocean interannual variability in the tropical Pacific, albeit much weaker and only qualitatively similar in pattern to that which is observed. Hence, overall, simulating interannual variability in the presence of an annually varying sun continues to be a difficult problem: there have been models that reproduce interannual SST variability and models that reproduce the annual cycle but reproduction of the full spectrum of variability remains elusive. (It should be recalled that the annual cycle is an average over all the variability present in the system [i.e., the average of all Januarys, Februarys, etc.] so that the annual cycle is not independent of interannual variability.)

The basic problem is that the processes that determine the annual cycle appear to be different from the processes that determine the interannual variability. In particular, we now believe that interannual SST variability in the Pacific depends in an essential way on wind-driven thermocline variations with heat fluxes at the surface acting mainly to damp the interannual perturbations [e.g., Barnett et al., 1991]. Annual variations of SST depend critically on heat flux variations at

\footnotetext{
${ }^{3}$ These models share with most other coupled atmosphere/ocean models a warm bias in the simulated climatology of the far eastern tropical Pacific [Mechoso et al., 1995].
} 
the surface and therefore depend in an essential way on radiative and cloud feedbacks (see, e.g., Koeberle and Philander [1994]). The treatment of low level stratus clouds seems to have given particular problems. These clouds exhibit a positive feedback to SST at low tropical SSTs and therefore induce a special sensitivity. They are generally dealt with poorly in existing models. Finally, vertical mixing is presently poorly represented in the current generation OGCMs used for tropical studies (but see Gent and Cane [1989] and McWilliams and Gent [1994]). This has a deleterious impact on the simulated SST in the eastern equatorial Pacific, where the changes in the meridional wind stress play a key role in causing annual SST variability [Mitchell and Wallace, 1992; Xie, 1995].

3.3.2. Interactions between ENSO and the seasonal cycle. In some recent studies, investigators have postulated that an annual cycle forcing of the coupled atmosphere/ocean system is responsible for the irregularity of ENSO events [Tziperman et al., 1994; Jin et al., 1994; Chang et al., 1994]. In these studies, a study of the coupled interannual variability is performed by arbitrarily increasing the annual cycle of a favorite parameter or the coupling strength between the atmosphere and ocean. The interannual variability in the models is periodic with no annual cycle forcing, but as the parameter is increased the frequency of the interannual variability increases through a sequence of rational fractions of the annual cycle: the ENSO cycle remains phase-locked to the annual cycle. The transition to higher frequencies is characterized by chaotic variability. In each of these studies, the physics associated with the ENSO mode appears to remain robust (e.g., in Jin et al., the ENSO mode is characterized by the delayed oscillator physics) as the forcing is increased.

Each of the studies mentioned above uses a different atmosphere/ocean model ${ }^{4}$ to argue for the importance of the seasonal cycle in producing irregularity of ENSO. We caution that even in the chaotic regime under modest forcing, the aforementioned models have spectra that are relatively peaked compared to the spectra from nature. In addition, in none of these studies is the annual cycle actually forced by the sun: the amplitude of a parameter or process with an annual cycle is artificially changed in these studies rather than a change in annual cycle of insolation. Nonetheless, these preliminary studies may lead to some insight as to how the annual cycle might interact with the model ENSO.

In contrast to the signal analysis approach taken in the three studies just discussed, Xie [1995] has suggested a physical mechanism of interaction between the ENSO mode and the seasonal cycle, based on the very different physical processes that seem to govern the interannual ENSO mode and the annual cycle (see, e.g., Koeberle and Philander [1994]). Xie finds a deepening of

\footnotetext{
${ }^{4}$ Tziperman et al. and Jin et al. use paradigm models, while Chang et al. use an intermediate level atmosphere/ocean numerical model.
}

the thermocline in the warm phase of ENSO reduces the amplitude of the annual cycle in SST (and vice versa), leading to a phase-locking of ENSO to the seasonal cycle.

\subsection{Optimal Growth, ENSO Prediction and ENSO Physics}

Blumenthal [1991] provided the first study of the optimal growth properties in the tropical Pacific using the output from the freely evolving coupled atmosphere/ocean model of Zebiak and Cane [1987]. The optimal perturbations were determined by deriving an linear autoregressive (Markov) model from a reduced set of the output variables. In this study, Blumenthal found that when a fixed amplitude perturbation is applied to the model (output), the maximum error growth over a nine-month time period is realized when the perturbation is applied in February. He also noted that the dependence of the error growth on season is consistent with the seasonal dependence of forecast skill reported by Cane et al. [1986].

Penland and Sardeshmukh [1995] have built a similar autoregressive model from the observed SST. In contrast to Blumenthal, they report that error growth is not a function of season and hypothesize that ENSO results from white noise forcing of a globally stable linearized system. At first glance, these results seem at odds with the results of Blumenthal using model output. Unfortunately, the results of these two studies cannot be directly compared because Penland and Sardeshmukh used only SST data in their model, while Blumenthal included in his Markov model SST, thermocline, and wind. Of concern, however, is that the Penland and Sardeshmukh [1995] Markov model requires that the ocean dynamics be equilibrated on timescales that are rapid compared with the SST changes. The analyses of the observations by Clarke and $L i$ [1994] and of the ocean hindcasts reported by Mantua and Battisti [1994a] indicate this assumption is not valid for the majority of the ENSO cycle: starting from a few months prior to the peak of an ENSO and extending through the event peak, the event demise and into the cold phase of the ENSO cycle, the observations are consistent with the delayed oscillator physics for ENSO. Thus, it is not surprising that Penland and Sardeshmukh found that the Markov model could not predict with skill the termination of ENSO events.

The studies of Blumenthal [1991] and Penland and Sardeshmukh [1995] come to somewhat disparate conclusions concerning the predictability and stability of the coupled atmosphere/ocean system. Nonetheless, both studies suggest that the traditional approach to assessing the variability in the atmosphere/ocean systemidentification of the fastest growing normal modes may not be the most instructive for understanding the predictability of the system. If one writes in matrix form the evolution equations for the linearized coupled atmosphere/ocean system $X$ : 


$$
\frac{\partial \vec{X}}{\partial t}=L \vec{X}
$$

it becomes immediately obvious that the normal modes of the system (the eigenvectors of $L$ ) can not be orthogonal (i.e., $L$ is not Hermitian) because of the coupling. ${ }^{5}$ Thus, the fastest growing normal mode will not, in general, determine the maximum error growth in the coupled models; forecast skill is better explained by a study of the projection of the initial conditions on the optimal perturbations. More on the theory of the non-selfadjoint modes and the theory of predictability can be found in Farrell [1990].

\section{Predicting ENSO}

\subsection{Predictions of ENSO}

The first coupled atmosphere-ocean forecast of short term (i.e., months to years) climate was made soon after the development of a simplified coupled model to simulate the ENSO phenomenon. This forecast, which predicted the growth of warm SST in the tropical Pacific one year before the onset of the 1986/7 warm phase of ENSO [Cane et al., 1986], is as important for climate forecasting as the first prediction using the barotropic vorticity equation was to weather forecasting. Since that time, the field of short term climate forecasting, especially as related to ENSO, has grown and prospered.

We now know, from numbers of statistical and dynamical forecasts, that there is skill in forecasting the SST in the central and eastern Pacific up to a year in advance (see Barnston et al. [1994] and Latif et al. [1994] for up-to-date reviews). The skill depends on the model and the methods of initialization. Models that are initialized solely by blowing winds over the ocean until the initial time and then coupling to the atmosphere generally have nowcast (i.e., initial) correlation skills of about 0.8 for the NINO3 index ${ }^{6}$ and then maintain useful correlation skills out to about a year.

Figure 1 shows the time dependent forecast skill for the Zebiak and Cane [1987] coupled model. Skills drop off considerably when forecast through the spring regardless of the month begun: this drop of skill through the spring has been called the "predictability barrier." Webster and Yang [1992] suggest that this is an intrinsic barrier to climate predictions in the tropics. Recently, however, Rosati et al. [1995] have successfully scaled the barrier in limited numbers of forecasts by assimilating ocean thermal data into the initial conditions for the forecast. And Chen et al. [1995] find no spring barrier when they "nudge" the Zebiak and Cane coupled model winds toward the observed winds in generating forecast initial conditions, whereby NINO3 skill correlations greater than 0.6 were obtained for lead times up

\footnotetext{
${ }^{5}$ In general, a spatially varying mean state is also sufficient to create a non-self-adjoint system.

${ }^{6}$ The NINO3 index refers to the SST anomaly, averaged from $5^{\circ} \mathrm{S}$ to $5^{\circ} \mathrm{N}$ and $150^{\circ} \mathrm{W}$ to $90^{\circ} \mathrm{W}$.
}

to 12 months, independent of the month from which the forecast is initiated.

Large, robust changes in the precipitation and wind patterns are concurrent with SST changes in the tropical regions. We may therefore confidently say that skill in predicting tropical SST implies skill in predicting precipitation and winds in the tropics. But extratropical effects of tropical SST changes are far more problematic. For example, Mo and Kalnay [1991] examined the impact on the midlatitude forecast skill of tropical SST anomalies from one cold (1988) and one warm (1987) ENSO event. They report only modest improvements in the ensemble long-range (10-30 day) forecast skill for the midlatitude Northern Hemisphere early summer circulation. While there are discernible and undeniable correlations of extratropical precipitation with tropical Pacific SST (Ropelewski and Halpert [1987], for example), these correlations have not yet led to usable skills in prediction.

A novel approach to this problem is the so-called "two tiered" forecasting system [Bengtsson et al., 1993; Hunt et al., 1994; Graham and Barnett, 1994]. SST predictions are made with relatively simple models and the SST so predicted is then used as the lower boundary conditions for a high resolution atmospheric GCM. While the forecast of $500 \mathrm{mb}$ height, say, shows apparent skill, the sensitivity of the midlatitude response is such that ensembles of atmospheric forecasts using slightly different initial conditions must be made to define the envelope of the predicted variability [Barnett et al., 1994]. The technique has been applied in a nowcasting mode by Graham [1994], where the current SST anomaly in the Pacific and Atlantic is used as a fixed boundary condition for high resolution atmospheric GCM simulations of the rainfall over eastnortheast Brazil.

\subsection{TOGA Program on Prediction (T-POP)}

Much of the U.S. progress in short term climate forecasting has been as a result of a concerted and focussed effort. The TOGA Program on Prediction (T-POP) was instituted in the U.S. in 1991 as a distributed research program and was designed to develop prediction systems, to develop methods of data assimilation for analysis and initialization, and to do the modeling and theoretical research needed to delineate and advance the theory of predictability of the climate on seasonal-to-interannual time scales [see Cane and Sarachik, 1991]. T-POP has provided a forum for the development of short term climate prediction systems and has instituted an intercomparison of forecasts by different groups for the common period 1985-1990. Under NOAA funding, it supports all the seasonalto-interannual forecast development activities in the United States.

\section{Applications of ENSO Predictions}

The impacts of interannual climatic variability on the countries surrounding the tropical Pacific are large and these countries hrve had no choice but to adapt. 


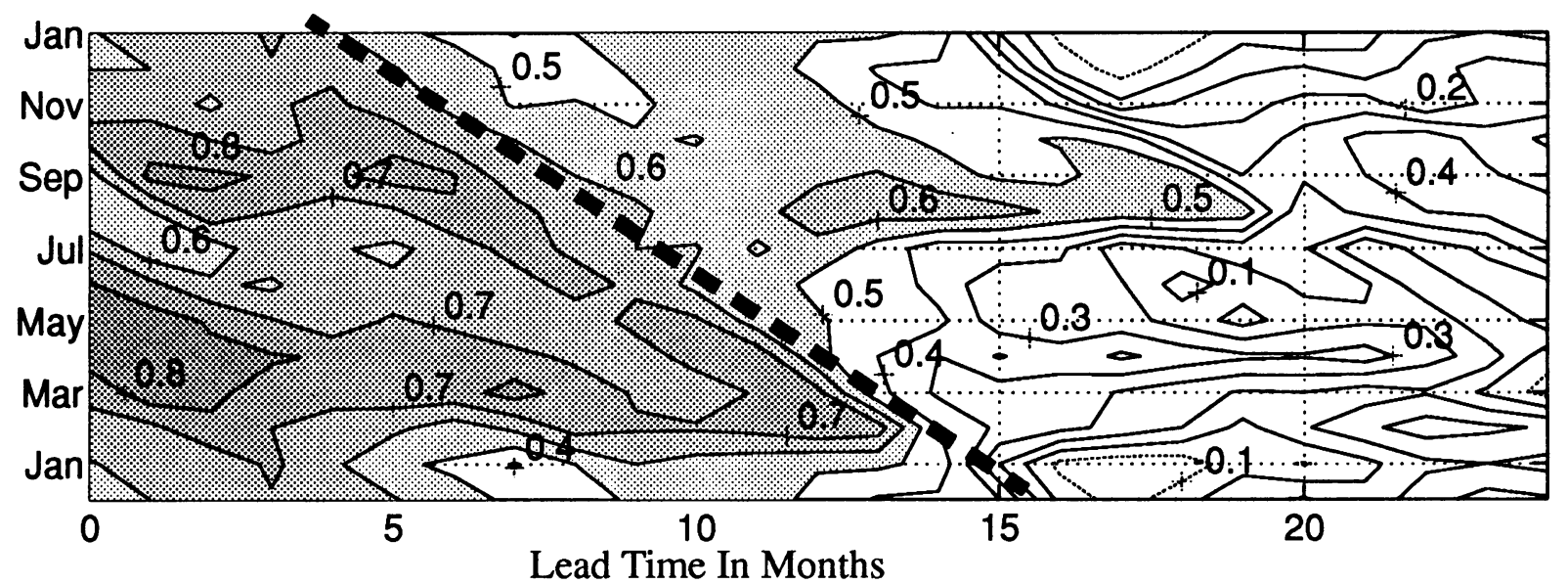

Figure 1. Anomaly correlations, plotted as a function of initialization month and forecast lead time, for six-month ensemble NINO3 forecasts from January 1970 through December 1990 from the Zebiak and Cane [1987] numerical model. Figure from Xue et al. [1994]. NINO3 is defined as the area averaged SST anomaly, from $5^{\circ} \mathrm{S}$ to $5^{\circ} \mathrm{N}, 150^{\circ} \mathrm{W}$ to $90^{\circ} \mathrm{W}$. The March isoline is indicated by the heavy dashed line.

\subsection{Fisheries}

The impacts of ENSO on coastal fisheries off South America are profound and mostly detrimental [e.g., Jordan, 1991]. Miller and Fluharty [1992] provide a complete analysis of the impacts of ENSO on the salmon fisheries of the Pacific. Impacts of the large 1982/3 warm phase of ENSO on corals, fisheries, and other marine organisms have been documented in Glynn [1992].

Forecasts of tropical SST a year in advance are clearly of direct value to fisheries in the productive regions of Ecuador, Peru, and Chile. While the involved countries are not yet organized enough to take advantage of this information, the foreknowledge of probabilities of anchoveta catches would allow, for example, more stable pricing strategies for world supplies of cattle protein and would forgo the type of rapid rise of cattle protein prices after the 1982/3 warm phase of ENSO [BahnerBenedict, 1992].

\subsection{Peru}

By and large, the agrarian based countries of the tropics are at the mercy of climate variability and skillful predictions of this variability mean a great deal to these countries. There is sufficient skill demonstrated in the existing forecasts that these forecasts are already being used for agricultural planning in Peru [Lagos and Buizer, 1992]. The rainy season, and therefore the growing season, in coastal northwest Peru is January to April and is primarily determined by the seasonal march of the eastern Pacific Intertropical Convergence Zone (ITCZ). Precipitation anomalies in this region are known to correlate extremely well with the SST anomalies characteristic of ENSO. By law, Peru must produce an agricultural plan each year, which determines the allocation of crops, seeds, water, power, etc. This plan is heavily influenced by existing ENSO predictions: a prediction of warm and wet implies a shift to rice cultivation while a prediction of cold and dry shifts the allocations to cotton. The prediction need only be avail- able a few months before the start of the growing season and, since the ENSOs in the last decade have been of the type that grow first in the equatorial Pacific and then in coastal South America, these predictions have been successful and have succeeded in increasing total agricultural output.

\subsection{Brazil}

The northeastern part of Brazil (in particular the state of Ceará) is semiarid, has a rainy season from February to April, and is subject to wide rainfall fluctuations from year to year. Throughout Brazilian history, especially dry periods have been marked by severe social dislocations and mass migrations which have affected the 30 million people of Ceará and the entire social and economic fabric of Brazilian culture.

Statistical correlations of rainfall with climatic indices [Hastenrath, 1990] have indicated that such rainfall is correlated with SST in both the Atlantic and the eastern Pacific. Realizing the vulnerability of its economy to such interannual climate fluctuations, the state of Ceará, in conjunction with the federal government, set up an institute, FUNCEME (Fundadação Cearense de Meteorologia e Recursos Hidricos), to advise the state on the proper actions to take in anticipation of adverse climatic conditions. FUNCEME has published a monthly information bulletin (Monitor Climático) since 1987 which gives monthly global climatic data, ENSO predictions, and specifically local precipitation and hydrological data.

FUNCEME maintains programs that address both long and short term issues. On the long term, it advises about actions to be taken on water resources and distribution, well recovery, crop choices and distribution, soil conditions, and environmental degradation. On the short term, it issues forecasts for the rainy season and explicit instructions to the various regions of Ceará about the timing of planting and about which 
crops to emphasize, depending on the forecast of abundant or deficient rainfall.

As a result of these actions, the agricultural output of Ceará has shown a gradual leveling effect, no longer subject to the drastic ups and downs of interannual climatic variability [Moura, 1994]. For example, the normal grain output for normal rainfall years in Ceará is 650,000 metric tons. In 1987 , before concerted action policies were in place, the response to a poor rainfall year ( $30 \%$ below normal) was a grain production for that year of 100,000 metric tons, which led to severe hardship in Ceará and the necessity of central governmental relief. In 1992, however, the rainfall was equally poor ( $27 \%$ below normal) but a set of concerted actions in response to a relatively accurate forecast allowed the grain production to be 530,000 tons. Even with a second consecutive poor rainfall year (again relatively accurately forecast) the grain production was 250,000 tons. $^{7}$

\subsection{The United States}

Within the U.S., applications of ENSO forecasts have been relegated to individual initiative. While correlations of measures of ENSO with temperature and precipitation over the U.S. exist, it is not at all clear that these correlations will lead to useful forecast skill. If skillful ENSO forecasts could be demonstrated for the U.S., their impact would be considerable [Adams et al., 1995].

\subsection{Australia}

Simpson et al. [1993] determined that there is a high correlation between ENSO events and significant decreases in the annual precipitation over eastern Australia. Using this information and the forecasts from the Zebiak and Cane [1987] atmosphere/ocean coupled model, Simpson et al. [1993] provided a nine-month forecast for the Murray river runoff. The Australian Bureau of Meteorology has been using the forecasts from the numerical models to issue useful "outlooks" for the seasonal precipitation anomalies. The success of these forecasts has led the Queensland State Government to sponsor the formal infrastructure to disseminate this information to farmers.

\section{The Next Four Years}

The observing system is in place, the models are ready, the applications are beginning to be appreciated: the next four years will see a flourish of activity in bringing the field of short term (up to one year) climate prediction to fruition.

As the TOGA program winds down, the international CLIVAR (Climate Variability and Predictability) Program and its U.S. contribution, GOALS (Global

\footnotetext{
${ }^{7}$ Much of the material cited for northeast Brazil has been provided by Dr. Antonio Moura and by Dr. Francisco Viana, President of FUNCEME.
}

Ocean Atmosphere Land System) will begin. Both have seasonal-to-interannual prediction as their foci and both are committed to perfecting and expanding the prediction capabilities through programs of observing, modeling, and predicting.

One of the basic issues the national and international communities will have to deal with is the proper institutional form that these regular and systematic prediction activities will take. In a recent proposal commissioned by the Inter-governmental TOGA Board [Moura, 1992], an International Research Institute for climate prediction (IRI) was proposed to perfect the science of climate prediction; to make the best possible predictions using the best possible prediction systems; and to interact with those countries that need such predictions in a partnership mode such that their applications needs are understood and properly dealt with. The US agreed to lead the effort to begin such an Institution and it was recognized that such an Institution, as well as the national efforts currently underway at the $\mathrm{Na}$ tional Meteorological Center, can serve as a national and international focus for prediction and applications research. The next four years will see whether or not such a concept can indeed be implemented.

Acknowledgments. We are grateful for the critical reviews by the following scientists: M. Cane, D. Neelin, C. Penland, P. Sardeshmukh, S.-P. Xie, and an anonymous reviewer. Editorial comments by $R$. Pielke helped make the paper more readable. This work was supported by grants from the NOAA Office of Global Change Programs.

\section{References}

Adams, R.M., K.J. Bryant, B.A. McCarl, D.M. Legler, J.J. O'Brien, A. Solow, and R. Weiher, The value of improved long-range weather information: Southeastern U.S. ENSO forecasts as they influence U.S. agriculture, Contemporary Economic Policy, in press, April, 1995.

Bahner-Benedict, Weather, US-EC clash affect oils mart, in Chemical Marketing Reporter, 242, 20, 1992.

Barnett, T.P., L. Dumenil, U. Schlese, E. Roeckner and M. Latif, The effect of Eurasian snow cover on regional and global climate variations, J. Atmos. Sci., 46, 661-685, 1989.

Barnett, T. P., M. Latif, E. Kirk and E. Roeckner, On ENSO physics, J. Climate, 4, 487-515, 1991.

Barnett, T.P., L. Bengtsson, K. Arpe, M. Flügel, N. Graham, M. Latif, J. Ritchie, E. Roeckner, U. Schlese, U. Schulzweida, and M. Tyree, Forecasting global ENSOrelated climate anomalies, Tellus, 46, 381-397, 1994.

Barnston, A.G., H.M. Van den Dool, S.E. Zebiak, T.P. Barnett, M. Ji, D.R. Rodenhuis, M.A. Cane, A. Leetmaa, N.E. Graham, C.R. Ropelewski, V. E. Kousky, E.A. O'Lenic, and R.E. Livezey: Long-lead seasonal forecastswhere do we stand?, Bull. Am. Met. Soc., 75, 2097-2114, 1994.

Battisti, D.S., and A.C. Hirst, Interannual variability in the tropical atmosphere-ocean system: Influence of the basic state, ocean geometry, and nonlinearity, J. Atmos. Sci., 46, 1687-1712, 1989.

Bengtsson, L., U. Schlese, E. Roeckner, M. Latif, T.P. Barnett, and N. Graham, A two-tiered approach to climate forecasting, Science, 261, 1026-1029, 1993. 
Blumenthal, M.B., Predictability of a coupled atmosphereocean model, J. Climate, 4, 766-784, 1991.

Cane, M.A., S.E. Zebiak, and S.C. Dolan, Experimental forecasts of El Niño, Nature, 321, 827-832, 1986.

Cane, M.A., and E.S. Sarachik, co-Chairpersons of The Provisional Working Group, Prospectus: A TOGA Program on Seasonal to Interannual Prediction, NOAA Climate and Global Change Program Special Report No. 4, UCAR Productions, 46 pp., 1991.

Chang, P., B. Wang, T. Li, and L. Ji, Interactions between the seasonal cycle and ENSO-frequency entrainment and chaos in a coupled atmosphere-ocean model, Geophys. Res. Lett., 21, No. 25, 2817-2820, 1994.

Chen, D., S. E. Zebiak, A. J. Busalacchi and M. A. Cane, An improved Procedure for El Niño Forecasting, submitted to Science, 1995.

Clarke, A.J. and B. $\mathrm{Li}$, On the timing of warm and cold $\mathrm{El}$ Niño/Southern Oscillation Events, in press, J. Climate, 1994.

Cole, J.E., and R.G. Fairbanks, The Southern Oscillation recorded in the $\delta^{18} \mathrm{O}$ of corals from Tarawa Atoll, Paleoceanography, 5, 669-683, 1990.

Cole, J.E., R.G. Fairbanks, and G.T. Shen, Recent variability in the Southern Oscillation: isotopic results from a Tarawa Atoll coral, Science, 260, 1790-1793, 1993.

Farrell, B.F., Small error dynamics and the predictability of atmospheric flows, J. Atmos. Sci., 47, 2409-2416, 1990.

Gent, P.R. and M.A. Cane, A reduced gravity, primitive equation model of the upper equatorial ocean, J. Computational Phys., 81, 444-480, 1989.

Gill, A.E., Elements of coupled ocean-atmosphere models for the tropics, Coupled Ocean-Atmosphere Models, edited by J.C.J. Nihoul, Elsevier Oceanogr. Ser., 40, pp. 303-327, Amsterdam, 1985.

Glanz, M.H., R.W. Katz and N. Nicholls (Eds.), Teleconnections Linking Worldwide Climate Anomalies, 535 pp., Cambridge University Press, Cambridge, 1991.

Glynn, P.W. (Ed.), Global Ecological Consequences of the 1982-83 El Niño-Southern Oscillation, 563 pp., Elsevier Oceanography Series No. 52, Elsevier Press, Amsterdam, 1990.

Goswami, B.N. and J. Shukla, Predictability of a coupled ocean-atmosphere model, J. Climate, 4, 107-115, 1991.

Graham, N., Experimental predictions of wet season precipitation in Northeastern Brazil, Proc. of the Climate Diagnostics Workshop of 1993, in press, 1994.

Graham, N., and Barnett, T.P., ENSO and ENSO related predictability. Part II: Northern hemisphere 700 millibar height predictions based on a hybrid coupled ENSO model, J. Climate, submitted, 1994.

Graham, N., T.P. Barnett, M.A. Cane and S.E. Zebiak, Simulated greenhouse warming and model ENSO cycles, $S I O$ Ref. Series, 94-04., 17 pp., 1994.

Hastenrath, S., Prediction of Northeast Brazil Rainfall Anomalies, J. Climate, 3, 893-904, 1990.

Hayes, S. P., L. J. Mangum, J. Picaut, A. Sumi and K. Takeuchi, TOGA-TAO: A moored array for real-time measurements in the tropical Pacific Ocean, Bull. Am. Meteor. Soc., 72, 339-347, 1991.

Hirst, A.C., Unstable and damped equatorial modes in simple coupled ocean-atmosphere models, J. Atmos. Sci., 43, 606-630, 1986.

Hirst, A.C., Slow instabilities in tropical ocean basin-global atmosphere models, J. Atmos. Sci., 45, 830-852, 1988:

Hunt, B.G., S.E. Zebiak and M.A. Cane: Experimental predictions of climatic variability for lead times of twelve months, International Journal of Climatology, 14, 507$526,1993$.

Jin, F.-F., and D. S. Neelin, Modes of interannual tropi- cal ocean-atmosphere interaction-a unified view. Part I: Numerical results, J. Atmos. Sci., 50, 3477-3503, 1993a.

Jin, F.-F, and D. S. Neelin, Modes of interannual tropical ocean-atmosphere interaction-a unified view. Part III: Analytical results in fully-coupled cases, J. Atmos. Sci., 50, 3523-3540, 1993b.

Jin, F.-F., J.D. Neelin, and M. Ghil, El Niño on the Devil's Staircase: Annual subharmonic steps to chaos, Science, 264, 70-72, 1994.

Jordan, R.S., Impact of ENSO events on the southeastern Pacific region with special reference to the interaction of fishing and climate variability, in Teleconnections Linking Worldwide Climate Anomalies, edited by M.H. Glantz, R.W. Katz, and N. Nicholls, pp. 401-430, Cambridge University Press, Cambridge, 1991.

Kessler, W.S., Can reflected extra-equatorial Rossby waves drive ENSO?, J. Phys. Oceanogr., 21, 444-452, 1990.

Knutson, T.R., and S. Manabe, The impact of increased $\mathrm{CO}_{2}$ on ENSO-like phenomena in a coupled ocean-atmosphere system, Geophys. Res. Lett., 21, 2295-2298, 1994.

Koeberle, and S.G.H. Philander, Seasonal Variations of sea surface temperatures in the tropical Pacific Ocean, Tellus, 46, 481-496, 1994.

Lagos, P., and J. Buizer, El Niño and Peru: A nation's response to interannual climate variability, in Natural and Technological Disasters: Causes, Effects, and Preventative Measures, edited by S.K. Majumdar, G.S. Forbes, E.W. Miller, and R.F. Schmaltz, pp. 223-238, The Pensylvania Academy of Science, 1992.

Latif, M., A. Sterl, E. Maier-Reimer and M. M. Junge, Climate variability in a coupled GCM. Part I: The tropical Pacific, J. Climate, 6, 5-21, 1993.

Latif, M., T.P. Barnett, M.A. Cane, M. Flügel, N.E. Graham, H. von Storch, J.-S. Xu, and S.E. Zebiak, A review of ENSO prediction studies, Climate Dynamics, 9, 167$179,1994$.

Lau, N.-C., S. G. H. Philander and M. J. Nath, Simulation of El Niño/Southern Oscillation phenomenon with a lowresolution coupled general circulation model of the global ocean and atmosphere, J. Climate, 5, 284-307, 1992.

Lea, D.W., G.T. Shen and E.A. Boyle, Coralline barium records temporal variability in equatorial Pacific upwelling Nature, 340, 373-6, 1989.

Leetmaa, A., and M. Ji, Operational hindcasting of the Tropical Pacific, Dyn. Atmos. Ocean., 13, 465-490, 1989.

Legrand, M., and C. Feniet-Saigne, Methanesulfonic acid in south polar snow layers: a record of strong El Niño?, Geophys. Res. Lett., 18, 187-190, 1991.

Li, B., and A.J. Clarke, An examination of some ENSO mechanisms using interannual sea level at the eastern and western equatorial boundaries and the zonally averaged equatorial wind, J. Phys. Oceanogr., 24, 681-690, 1994.

Mantua, N.J., Numerical Modeling Studies of the El Niño/Southern Oscillation, 139 pp., Ph. D. Thesis, Univ. of Washington, Seattle, pp. 139, June 1994.

Mantua, N.J. and D.S. Battisti, Evidence for the delayed oscillator mechanism for ENSO: The "observed" oceanic Kelvin mode in the far western Pacific, J. Phys. Oceanogr. 24, 691-699, 1994a.

Mantua, N.J. and D.S. Battisti, Aperiodic variability in the Zebiak-Cane coupled ocean-atmosphere model: oceanatmosphere interactions in the western equatorial Pacific, revised, J. Climate, 1994 b.

Mass, C.F. and D.A. Portman, Major volcanic eruptions and climate: a critical evaluation, J. Climate, 2, 566-593, 1989.

McWilliams, J.C. and P.R. Gent, The wind-driven ocean circulation with an isopycnal-thickness mixing parameterization, J. Phys. Oceanogr., 24, 46-65, 1994. 
Mechoso, C.R., A.W. Robertson, N. Barth, M.K. Davey, P. Delecluse, P.R. Gent, S. Ineson, B. Kirtman, M. Latif, H. Le Treut, T. Nagai, J.D. Neelin, S.G.H. Philander, J. Polcher, P.S. Schopf, T. Stockdale, M.J. Suarez, L. Terray, O. Thual and J.J. Tribia, The seasonal cycle over the tropical Pacific in coupled ocean-atmosphere general circulation models, in press, Mon. Weather Rev., 1995.

Meehl, G.A., G.W. Branstator, W.M. Washington, Tropical Pacific interannual variability and $\mathrm{CO}_{2}$ climate change, $J$. Climate, 6, 42-63, 1993.

Miller, K.A., and D.L. Fluharty, El Niño and variability in the northeastern Pacific salmon fishery: implications for coping with climate change, in Climate Variability, Climate Change, and Fisheries, edited by M.H. Glantz, pp. 49-88, Cambridge University Press, 1992.

Mitchell, T.P, and J.M. Wallace, The annual cycle in equatorial convection and sea surface temperature, J. Climate, $5,1140-1156,1992$.

Mo, K.C., and E. Kalnay, Impact of sea surface temperature anomalies on skill of monthly forecasts, Mon. Weather Rev., 119, 2771-2793, 1993.

Moura, A., and the Task Group, International Research Institute for Climate Prediction: A Proposal. Available from the NOAA/Office of Global Programs, 1100 Wayne Ave., Suite 1225, Silver spring, MD., 20910, 1992.

Moura, A.D, Prospects for seasonal-to-interannual climate prediction and applications for sustainable development. World Meterological Society Bulletin, 43, 207-215, 1994.

Munnich, M, M.A. Cane and S.E. Zebiak, A study of selfexcited oscillations of the tropical ocean-atmosphere system. II. Nonlinear cases, J. Atmos. Sci., 48, 1238-1248, 1991.

Nagai, T., T. Tokioka, M. Endoh and Y. Kitamura, El Niño/Southern Oscillation simulated in an MRI atmosphere-ocean coupled general circulation model, J. Climate, 5, 1202-1233, 1992.

National Research Council, Ocean-Atmosphere Observations Supporting Short-Term Climate Predictions, 51 pp., National Academy Press, Washington, 1994.

Neelin, J.D., and F.-F. Jin, Modes of interannual tropical ocean-atmosphere interaction-a unified view. Part II: Analytical results in the weak-coupling limit, J. Atmos. Sci., 50, 3504-3522, 1993.

Neelin, J.D., M. Latif and F.-F Jin, Dynamics of Coupled Ocean-Atmosphere Models: The Tropical Problem, Annu. Rev. Fluid Mech., 26, 617-659, 1994.

$\mathrm{Ng}, \mathrm{M} . \mathrm{K} . \mathrm{F}$., and W.W. Hsieh, The equatorial Kelvin wave in finite difference models, J. Geophys. Res., 99, 1417314185, 1994.

Penland, C., and T. Magorian, Prediction of Niño 3 Sea Surface Temperatures using linear inverse modeling, $J$. Climate, 6, 107-176, 1993.

Penland, C., and P.D. Sardeshmukh, The optimal growth of tropical sea surface temperature anomalies, in press, $J$. Climate, 1995.

Philander, S.G.H., T.Yamagata, and R.C. Pacanowski, Unstable air-sea interactions in the tropics, J. Atmos. Sci., 41, 604-613, 1984.

Philander, S.G.H., R.C. Pacanowski, N.C. Lau, and M.J. Nath, A simulation of the Southern Oscillation with a global atmospheric GCM coupled to a high-resolution, tropical Pacific Ocean GCM, J. Climate, 5, 308-329, 1992.

Rasmusson, E.M., and T.H. Carpenter, Variations in tropical sea surface temperature and surface wind fields associated with the Southern Oscillation/El Niño, Mon. Weather Rev., 110, 354-384, 1982.

Rasmusson, E.M., and J.M. Wallace, Meteorological aspects of the El Ninõ/Southern Oscillation, Science, 222, 1195$1202,1983$.
Robertson, A.W., C.-C. Ma, M. Ghil, and C.R. Mechoso, Simulation of the Tropical Pacific climate with a coupled ocean-atmosphere general circulation model. Part II: Interannual variability, J. Climate, in press (April), 1995.

Ropelewski, C.F., and M.S. Halpert, Global and regional scale precipitation patterns associated with the $\mathrm{El}$ Niño/Southern Oscillation, Mon. Weather Rev., 114, 2352-2362, 1987.

Rosati, A., K. Miyakoda, and R. Gudgel, The impact of ocean initial conditions on ENSO forecasting with a coupled model, in press, Mon. Weather Rev., 1995.

Shen, G.T., L.J. Linn, T.M. Campbell, J.E. Cole and R.G. Fairbanks, A chemical indicator of trade wind reversal in corals from the western tropical Pacific, J. Geoph. Res., 97, 12689-12697, 1992a.

Shen, G.T., J.E. Cole, D.W. Lea, L.J. Linn, T.A. McConnaughey, and R.G. Fairbanks, Surface ocean variability at Galapagos from 1936-1982: calibration of geochemical tracers in corals, Paleoceanography, 7, 563-588, $1992 \mathrm{~b}$.

Simpson, H.J., M.A. Cane, S.K. Lin, S.E. Zebiak and A.L. Herczeg, Forecasting annual discharge of River Murray, Australia, from a geophysical model of ENSO, J. Climate, 6, 386-390, 1993.

Stahle, D.W., and M.K. Cleaveland, Southern Oscillation extremes reconstructed from tree rings of the Sierra Madre Occidental and southern Great Plains, J. Climate, 6, 129140, 1993.

Suarez M.J., and P.S. Schopf, A delayed action oscillator for ENSO, J. Atmos. Sci., 45, 3283-3287, 1988.

Tziperman, E., L. Stone, M. Cane, and H. Jarosh, El Niño chaos: overlapping of resonances between the seasonal cycle and the Pacific ocean-atmosphere oscillator, Science, 264, 72-74, 1994.

Wakata, Y., and E.S. Sarachik, On the role of equatorial ocean modes in the ENSO cycle. J. Phys. Oceanogr., 21, 434-443, 1991.

Wakata, Y., and E.S. Sarachik, Unstable coupled atmosphereocean basin modes in the presence of a spatially varying basic state, J. Atmos. Sci., 48, 2060-2077, 1992.

Wallace, J.M., El Niño and climate prediction, Reports to the Nation on our Changing Planet, No. 3, 25 pp., UCAR, Boulder CO, 1994.

Webster, P.J., and S. Yang, Monsoon and ENSO: Selectively interactive systems, Quart. J. Roy. Met. Soc., 118, 877926, 1992.

Xie, S.-P., Interaction between the annual and interannual variations in the equatorial Pacific, in press, J. Phys. Oceanogr., 1995.

Xue, Y., M. A. Cane, S. E. Zebiak and M. B. Blumenthal, On the prediction of ENSO: A study with a low order Markov model, Tellus, 46, 512-528, 1994.

Yamagata, T., Stability of a simple air-sea coupled model in the tropics, in Coupled Ocean-Atmosphere Models, edited by J.C.J. Nihoul, pp. 637-657, Elsevier Oceanography Series No. 40, Elsevier, Amsterdam, 1985.

Zebiak, S.E. and M.A. Cane, A model El Niño/Southern Oscillation, Mon. Weather Rev., 115, 2262-2278, 1987.

Zebiak, S.E., On the 30-60 day oscillation and the prediction of El Niño, J. Climate, 2, 1381-1387, 1989.

D.S. Battisti, Department of Atmospheric Science, AK40, University of Washington, Seattle, WA 98198. (e-mail david@atmos.washington.edu)

E.S. Sarachik, Department of Atmospheric Science, AK40, University of Washington, Seattle, WA 98198. (e-mail sarachik@atmos.washington.edu)

(Received June 20, 1994; revised February 22, 1995; accepted February 27, 1995.) 